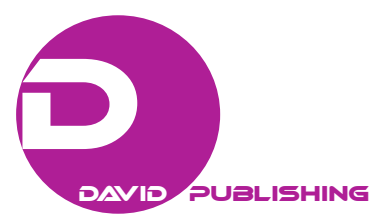

\title{
Development and Prospect of Guizhou-ASEAN Higher Education Cooperation and Exchange
}

\author{
Su Xiang-jun \\ Zunyi Medical University, Guizhou, China
}

\begin{abstract}
Economic globalization leads to educational internationalization. Thriving economic development in Asia, particularly the peaceful rise of China, promotes the interaction between China and Association of Southeast Asian Nations (ASEAN), creating more opportunities and challenges for both parties to cooperate in all fields. Against the backdrop of China-ASEAN strategic partnership, the internationalization of higher education, a pioneer in Guizhou's opening up, has become an important means for strengthening the connection between Guizhou and the outside world and accelerating the reform and development of Guizhou. Reviewing the higher education cooperation and exchange between Guizhou and ASEAN in the past 12 years, this article examines the achievements and insufficiencies in Guizhou-ASEAN higher education cooperation and exchange, and explores the current advantages and prospects for deepening Guizhou-ASEAN higher education cooperation and exchange in the future. It is argued that it would be the right direction for Guizhou to boost its higher education collaboration and development with ASEAN in the future by enlarging their collaborative scale, improving the quality of education, and highlighting its advantages and features in higher education internationalization.
\end{abstract}

Keywords: higher education, cooperation and exchange, Guizhou, Association of Southeast Asian Nations

\section{Introduction}

International education is an important indicator for evaluating the comprehensive strength of an economy in the globalized world. As is known to all, the internationalization of education plays a major role in boosting the globalized process of a country or a region. With the quick rise of China in economy, in recent years, its interactions with the world in higher education increase dramatically. According to the statistics released by the Ministry of Education in 2018, the overseas students studying in China come from 196 countries and regions, and are distributed in 1,004 higher education institutions among 31 provinces, regions, or municipalities across China, reaching 492,185 in enrollment number (Zhong, 2019). China's higher education is becoming more and more international, which greatly contributes to its economy-based national development by promoting mutual understanding among different nations.

China-Association of Southeast Asian Nations (ASEAN) higher education cooperation and exchange is a major component in the internationalization of China's education. The relevant data suggests that, by 2015, Chinese students in ASEAN countries have been above 120,000, and ASEAN students in China have exceeded 72,000 (Chen, 2016). And the numbers of the international students from both parties are growing very fast. In

Su Xiang-jun, Ph.D., associate professor, School of Foreign Languages, Zunyi Medical University. 
fact, China-ASEAN higher education cooperation and exchange is a significant international interaction between different peoples and cultures, which plays an active part in keeping the peace as well as boosting the economic prosperity in the region.

With China-ASEAN cooperation and development deepening, the internationalization of higher education in Guizhou province takes on a new look. This paper first reviews what Guizhou-ASEAN higher education cooperation and exchange has gone through in the past 12 years, then focuses on analyzing the achievements and the inadequacies in higher education collaboration, finally explores the prospects in higher education interaction for both parties in the future.

\section{Development of Guizhou Higher Education Internationalization}

\section{Economic and Social Development of Guizhou Province}

Being weak in opening up to the outside world for years is the underlying cause for the relative backwardness in economic and social development of Guizhou province. Due to the poor communications and transportation caused by mountainous terrain, the social development of Guizhou remains restricted for a long time. Most people in Guizhou had to adapt themselves to the disadvantageous surroundings and live with it or in poverty. Ever since, the reform and opening up policy implemented nationwide in 1978, the disadvantaged situation of Guizhou began to improve. Over the past decades, Guizhou committed itself to the economic and social development under the powerful support of the central government and its impoverishment and backwardness began to change.

In recent years, especially, the economic growth rate of Guizhou has been remaining on the top of the list after the opening-up policy was actively implemented by Guizhou provincial government, and its economic growth rate has ranked the first nationwide since 2017 (Huang, 2019). With the expansion of international communication and cooperation, dramatic social changes have taken place in Guizhou. Owing to its economic acceleration, both infrastructure and morale in Guizhou have been greatly improved. At present, Guizhou is speeding up its development in all walks of life to keep up with the other developed provinces in China.

\section{Higher Education of Guizhou}

Since the reform and opening up of China in 1978, especially over the recent 10 years, higher education in Guizhou develops quickly, producing more than 1,000,000 talents at all levels for economic and social development of China (Huo, 2011). Against the backdrop of the quick rise of China, the supportive role of higher education of Guizhou is becoming more and more powerful in boosting its local economy, science and technology, culture, etc. In general, however, the internationalization of higher education in Guizhou gets started later and legs behind the other provinces, and the overall level remains low, but it has advanced rapidly in the recent decade.

It can be said that the internationalization of higher education in Guizhou has begun after the new millennium arrived. From then on, a plethora of favorable policies and effective measures are hammered out, including the Great Western Development Strategy initiated in 2001, China-ASEAN Strategic Partnership established in 2003, especially China-ASEAN Education Cooperation Week (hereinafter abbreviated as CAECW) launched in Guizhou in 2008, and a series of moves on promoting economic and social development of Guizhou approved by the State Council in 2012, and so on. All these favorable factors contribute a lot to the quick development of higher education in Guizhou, particularly to the international cooperation of higher 
education between Guizhou and ASEAN.

\section{Evolution of Guizhou-ASEAN Higher Education Cooperation and Exchange}

In the past decade, Guizhou higher education spearheaded in accelerating economy and advancing society and expanding opening up to the outside world. In the social context, where Guizhou is set to catch up and overtake the economically prosperous regions by speeding up its development, Guizhou higher education internationalization develops rapidly. According to a statistics, more than 10 years ago, before the collaboration and exchange between Guizhou and ASEAN countries, there were only scores of international students studying in Guizhou, by contrast, there are now 4,000 overseas students scattering in the different universities and colleges, and an overwhelming majority of them, above 70\%, come from ASEAN countries (Wang, 2019; Ren, 2019). Thanks to good economic and political relations between China and ASEAN countries, Guizhou higher education internationalization shifts its focus from Europe and the U.S. to South and East Asia. Higher education of Guizhou has undergone many exciting changes in terms of international cooperation and exchange with ASEAN, when the CAECW was launched in Guizhou in 2008 and settled there permanently. Up to now, it has been 12 years since CAECW was held annually in Guizhou.

After 12 years of development, CAECW has developed into a model for cooperation and exchange between China and ASEAN countries, and also become a major platform of international interaction for Guizhou. The first meeting of CAECW was jointly held by the Foreign Ministry, the Ministry of Education, and Guizhou People's Government in Guiyang in 2008, which is the starting point for Guizhou-ASEAN higher education cooperation and exchange. Before that, interaction in higher education between Guizhou and ASEAN was rather limited. In 2008, only 27 ASEAN students studied in Guizhou University, the first school in Guizhou to enroll ASEAN students, whose interaction in higher education internationalization at that time mainly focused on Europe and the U. S. (Wang, 2015). Twelve years later, the scenario has been drastically changed: About 3,000 ASEAN students studying in more than 20 universities and colleges in Guizhou.

Over the 12 years, Guizhou-ASEAN higher education cooperation and exchange has been deepening all the way. It has grown in quantity, size, content, form, and others. Specifically, profound changes have taken place in the following aspects:

Thanks to the prosperous economic development of China and the strengthening political tie between China and ASEAN, the environment for China-ASEAN cooperation and exchange is improving for the internationalization of higher education in Guizhou. A large number of favorable policies and opportunities surge into Guizhou to speed up its social development. In recent 20 years, the environment of Guizhou-ASEAN higher education cooperation and exchange has been totally transformed. First, leaders of different levels are fully aware of the great power of higher education in pushing forward the opening up of Guizhou to the outside world and give their full support to the development of Guizhou-ASEAN higher education cooperation. Xi Jin-ping, general secretary of the communist party of China, instructed Guizhou to strengthen cooperation and exchange with ASEAN countries in May 2015, when he was visiting Guizhou for inspection and guidance. In addition, former party chiefs or governors of Guizhou, Li Zhan-shu, Zhao Ke-zhi, and Chen Min-er, and the current provincial party chief Sun Zhi-gang and provincial governor Shen Yi-qin, all emphasized the significance for the opening up Guizhou to the outside world and recognized the leading role of higher education internationalization in driving Guizhou forward. Second, a variety of supportive policies have become another impetus for promoting Guizhou-ASEAN higher education cooperation. In order to expand 
opening up of China, some important educational policies were promulgated, such as Proposals on the Opening up of Education in the New Era, Joint Construction of "the Belt and Road" Education Initiative, National Medium and Long-term Educational Reform and Development Program (2010-2020), Guizhou Medium and Long-Term Educational Reform and Development Program (2010-2020), etc., all of which contribute to Guizhou-ASEAN higher education cooperation and exchange.

The scale and scope of Guizhou-ASEAN higher education cooperation and exchange have been quickly expanded in the short time span of 12 years. In 2008, when the higher education cooperation between Guizhou and ASEAN countries was in its infancy, there were only scores of ASEAN students studying in Guizhou. Today, there are about 3,000 ASEAN students studying in most universities or colleges of Guizhou, making up above $70 \%$ of all the international students in Guizhou (Ren, 2019). In addition to Guizhou University, which is the representative of Guizhou higher education institutions and pioneer to enroll ASEAN students, there are now more than 20 schools taking in students from ASEAN countries, including Guizhou University of Finance and Economics, Guizhou Minzu University, Guizhou Normal University, Guizhou Medical University, Guizhou Electric Power Vocational Technology College, Zunyi Normal College, Zunyi Medical University, Tongren University, Tongren Polytechnic College, South Guizhou Normal University, and so on. The universities or colleges that admit ASEAN students extend beyond the capital city of Guiyang to the other cities in Guizhou. It is also worth mentioning that the opportunities to walk out to ASEAN are also on the rise. An increasing number of students and faculty members from Guizhou also go out to study, visit, or work in ASEAN countries, particularly in some economically prosperous countries, such as Singapore, Malaysia, and Thailand. And through Guizhou Thousand Students Study Abroad Program, which was launched by the Department of Education of Guizhou Province in 2014, more and more students from Guizhou have the opportunity to visit universities or colleges in ASEAN countries (Wang, 2019). Besides, the Department of Education of Guizhou Province organized and dispatched many work groups to visit, learn, research, and attend education expositions in ASEAN countries, and universities and colleges of Guizhou sent more than 200 students as Chinese teachers or volunteers to Thailand, Philippines, and some other ASEAN countries in the past 10 years (Zhang, Yang, Zhou, \& Hu, 2015).

The programs and courses for ASEAN students studying in Guizhou are getting richer and varied as the cooperations and exchanges between Guizhou and ASEAN are further strengthened. In the beginning of Guizhou-ASEAN higher education cooperation and exchange, when ASEAN students did not know much about the educational resources of Guizhou, most of them came to Guizhou mainly for studying Chinese and some very general programs or courses, such as literature, business, law, etc. (Zhang \& Hu, 2016). As the cooperation and exchanges deepen, more and more programs and courses are provided to meet their needs, especially those programs or courses, which can meet the urgent needs of their present social and economic development, including computer science, civil engineering, nursing, medicine, management, and so on. In addition to the regular education, vocational education is getting more and more popular to ASEAN students (Shen, 2002). Recently, ASEAN students studying in Guizhou have the tendency of becoming more and more practice-oriented in selecting what to study. Higher vocational education has been paid more and more attention in Guizhou-ASEAN collaboration and exchanges. For instance, National China-ASEAN Education Training Centers were founded first in Guizhou Electric Power Vocational Technology College in 2012 and later in Guizhou University in 2014 respectively to meet the demands of practical talent cultivation. 
A growing number of research institutions have been set up to support Guizhou-ASEAN higher education cooperation and exchange and more funds have been invested to attract more ASEAN students to study in Guizhou. In 2008, Guizhou University has been approved as Educational Foreign Aid Base of the Ministry of Education by the Ministry of Education, whose purpose is to enhance the cooperation and exchanges between Guizhou and ASEAN countries. In 2009, ASEAN Research Center was set up in Guizhou University, and later in 2013, was upgraded to be ASEAN Research Institute of Guizhou University, cultivating talents for China-ASEAN cooperation and development, offering information inquiry to the society, and serving as a think tank for the local government. In addition, some more institutions or platforms were built to increase the international interactions in higher education among the two parties, including China-ASEAN Educational Training Center, China (Guizhou)-ASEAN International Students Demonstration Base, China (Guizhou)-Malaysian Education Service Center, etc. To attract more ASEAN students to study in Guizhou, Guizhou People's Government set up Guizhou Foreign Students' Scholarship in 2013, which includes the special grant for ASEAN students. Moreover, additional financial supports are also available, such as Chinese Government's Scholarship and School Scholarships.

In sum, despite the great improvement in the overall level of Guizhou higher education internationalization, there is still a huge gap in terms of the cooperation and exchange with ASEAN when it is compared with its neighbors, i.e., Yunnan and Guangxi provinces.

\section{Inadequacies of Guizhou-ASEAN Higher Education Cooperation and Exchange}

\section{In Comparison With Its Neighboring Provinces: Guangxi and Yunnan}

As mentioned above, Guizhou-ASEAN higher education cooperation and exchange has just entered its rudimentary stage after more than 10 years of rapid development. At present, the higher education cooperation among the two parties is still characterized by small enrollment size, lack of variety, indistinctive advantage and feature, and other imperfections. These weaknesses can be more perceivably detected, when it is scrutinized in comparison with Yunnan and Guangxi.

Yunnan, Guangxi, and Guizhou have a natural advantage over the rest of our country in China-ASEAN cooperation and exchange, as they are geographically close to ASEAN countries, particularly the five countries on the central south peninsula, namely, Vietnam, Thailand, Laos, Cambodia, and Burma. Out of the three provinces adjacent to ASEAN countries, Guangxi enjoys the best advantage in both geographical location and cultural relations with ASEAN. Guangxi shares the border with Vietnam by land and by sea, Yunnan borders with Burma, Laos, and Vietnam, while Guizhou is only located near to ASEAN. For this reason, the higher education cooperation and exchange between Guangxi and ASEAN countries are carried out most successfully. By now, Guangxi is ranked first among all the provinces in enrolling ASEAN students (H. Lin \& Y. Lin, 2015).

In 2012-2015, the number of the ASEAN students studying in Guangxi has reached 37,346, which indicates Guangxi is the first choice for international students from ASEAN countries (H. Lin \& Y. Lin, 2015). By the end of 2014, there have been 190,000 China-ASEAN international students, of which there are 120,000 of them from China studying in ASEAN countries, and 70,000 from ASEAN countries in China (Lin, 2015). In recent five years, international students from ASEAN studying in Guangxi increased dramatically by the growth rate of $20 \%$, which is higher than the national average growth rate (Xia, 2018). It is reported that there are about 6,000 students from Guangxi studying abroad and 5,000 of them choose to study in ASEAN countries 
(Pang \& Xie, 2010).

To help ASEAN students adapt themselves to the surroundings in Guangxi, language study is attached great importance in the universities and colleges in Guangxi, including Chinese, English, Malay, and various languages of ASEAN countries. For this purpose, all languages used in ASEAN countries are taught in Guangxi University for Nationalities, in which the number of ASEAN students is the largest.

Yunnan is another major province that has a close higher education cooperation and exchange with ASEAN countries in China-ASEAN interactions. According to a statistics, by the end of 2018, there have been 19,300 international students coming to study in Yunnan, ranking the ninth on the list of enrolling foreign students in China, and 90\% of them came from ASEAN countries (Yu, 2019). Higher vocational education is given due attention in Yunnan-ASEAN higher education cooperation and exchange. Yunnan Minzu University joined hands with 38 vocational technology colleges in Yunnan to found Lancang River and Mekong River Vocational Education Alliance, which trained more than 20,000 students (Yu, 2019). Furthermore, Yunnan pays attention to international promotion of Chinese language by centering on the construction of "the Belt and Road" and "South Asia and Southeast Asia Radiation Center". Unlike the comprehensive and deeply integrated higher education cooperation and exchange pattern in Guangxi, Yunnan-ASEAN higher education cooperation and exchange is characterized by emphasizing the distinctive features and advantages of local educational resources.

\section{Differences Between Guizhou and Its Neighboring Provinces in Higher Education Cooperation and Exchange}

Compared with those in Guangxi and Yunnan, Guizhou-ASEAN higher education cooperation and exchange has the following inadequacies or disadvantages:

Guizhou-ASEAN higher education cooperation and exchange got started later as Guizhou did not enjoy the geographical advantage in comparison with its neighbors Guangxi and Yunnan. In the past, restricted by the numerous mountains and rivers, people living in Guizhou had little communication with the outside world due to the inconvenient transportation and their mind remained provincial. Not until the reform and opening up in 1978, especially in the 21st century, when a series of national development strategies were implemented one after another, including the Great Western Development Strategy (2001), China-ASEAN Strategic Partnership (2003), China-ASEAN Free Trade Area (2010), “the Belt and Road” Initiative (2013), the Twelfth Five-Year Plan (2011-2015), etc., Guizhou began to quicken its pace of economic and social development. To be exact, Guizhou-ASEAN higher education cooperation and exchange officially started in 2008, when CAECW was first held. In contrast, Yunnan-ASEAN higher education cooperation and exchange was launched in 2002, while Guangxi-ASEAN higher education cooperation and exchange in 2004.

The total number of ASEAN students in the universities and colleges of Guizhou is small although the enrollment scale is growing fast. Up to now, all the ASEAN students studying in Guizhou have not amounted to 10,000. In this respect, there is a huge disparity between Guizhou and its neighbors, namely, Guangxi and Yunnan, both of which have already taken in more than 10,000 students from ASEAN. Besides, there is no balance between "walk out" or outbound international students and "usher in" or inbound international students for Guizhou. Currently, the number of international students from Guizhou in ASEAN is smaller than that of the international students from ASEAN in Guizhou. However, as Guizhou Thousand Students Study Abroad Program was launched in 2014, students from Guizhou studying in ASEAN began to 
rise.

The structure and type of Guizhou-ASEAN higher education cooperation and exchange are still short of diversity. ASEAN students in Guizhou are mainly from some underdeveloped countries, such as Cambodia, Burma, Laos, etc. Few or no students came from Singapore, Malaysia, Indonesia, Brunei, etc. As the internationalization of Guizhou higher education progresses fast, the transfer from short-term exchange programs to diploma education occurs in Guizhou-ASEAN higher education cooperation and exchange. Currently, the undergraduate education remains the overwhelming majority for ASEAN students in Guizhou, whereas postgraduate education makes up only $2 \%$, especially doctoral education, which only accounts for a tiny part or unavailable in some programs (Zhu, Huang, \& Hu, 2018). What is worse, postgraduate education for ASEAN students is available only in Guizhou University. At this point, higher education cooperation and exchange in Guangxi and Yunnan seem to be more diverse and more reasonably distributed.

The development of Guizhou-ASEAN higher education cooperation and exchange is not well-balanced and extensively distributed. Due to historical reason, most higher education institutions in Guizhou are located at the capital city of Guiyang. Therefore, most relevant resources and opportunities have gone to Guiyang, making the internationalization of Guizhou higher education there develop more rapidly than other regions. Moreover, Guizhou University, as the only one "Project 211 University” in Guizhou (Project 211 is a project of national key universities and colleges initiated in 1995 by the Ministry of Education of the People's Republic of China), occupies the most part of Guizhou-ASEAN higher education cooperation and exchange. So, it has the absolute advantage over the other universities and colleges in carrying out cooperation and exchange with ASEAN countries. Many platforms to support the development of Guizhou-ASEAN higher education were also set up in Guizhou University, such as China-ASEAN Research Institute, Educational Foreign Aid Base of the Ministry of Education, China-ASEAN Vocational Education Training Center, and so on, causing the other universities or colleges in Guizhou to win less support. On the other hand, the comprehensive strength and the social influence of Guizhou University is another edge over other schools in political and financial supports.

The active role of language is rather weak and language education does not meet the demands of serving the social development. Language is the bridge to connect people to people. Ethnic groups and languages in ASEAN countries are diverse and complicated. For example, more than 700 languages are spoken in Indonesia alone (Kirkpatrick \& Liddicoat, 2017). Language is the powerful support for Guizhou-ASEAN higher education cooperation and exchange, but language's social service function and its role to promote economic development have not been given due attention. Firstly, international Chinese education in Guizhou is not powerful enough. Although the teaching of Chinese is available in the 21 schools in Guizhou, which are qualified to enroll foreign students, there are only three schools, where the Chinese Proficiency Test (HSK) is administered. And there are only two Confucius institutes abroad from Guizhou, and none of them was found in ASEAN countries (Zhang et al., 2015). By contrast, to date, Yunnan has 48 schools qualified for enrolling foreign students, seven HSK test centers, and 15 overseas Confucius institutes, while Guangxi has 37 schools eligible for enrolling foreign students, eight HSK test centers, and seven overseas Confucius institutes, most of which are located in ASEAN countries (Chen, 2018). Secondly, the current foreign language education of Guizhou cannot cultivate the talents that Guizhou needs in its economic and social development. Foreign language education programs can be found in the schools or departments of foreign languages in almost all the universities and colleges in Guizhou, but only a very small number of students can meet the requirements of 
economic and social development in Guizhou, because most of them are weak in language practical use. Since ASEAN is composed of 10 different countries, in which ethnic groups are varied and their languages are diverse, the languages of ASEAN countries can be roughly classified into three categories: English, Malay, and local language of each country (Chen, 2012). English, as lingua franca, has not been well taken advantage of in serving international cooperation and exchange in Guizhou. The qualified teachers, who teach ASEAN students both in Chinese and English in Guizhou higher education institutions, are extremely inadequate. English talents are usually hired from the language service companies from Beijing, Shanghai, etc., every time when there are some important international exchange activities being held in Guizhou. For this reason, English has become one of the biggest obstacles to speeding up Guizhou's international cooperation and exchange with the outside world. Meanwhile, apart from English, many others so-called "minor languages" used in ASEAN countries are also ignored. No ASEAN language programs are offered in universities and colleges of Guizhou except Guizhou University, whereas in Yunnan and Guangxi ASEAN language programs are extensively provided, especially in Guangxi University for nationalities and Yunnan Minzu University, where all ASEAN language courses are available.

In brief, despite the huge progress made since 2008, Guizhou-ASEAN higher education cooperation and exchange is still in its initial stage. In contrast to the achievements made in Guangxi and Yunnan, there still exists a huge gap in Guizhou-ASEAN higher education cooperation and exchange.

\section{Advantage and Prospect of Guizhou-ASEAN Higher Education Cooperation and Exchange}

\section{Advantages of Guizhou-ASEAN Higher Education Cooperation and Exchange}

Thanks to the rapid improvement of both international and domestic environments, the advantages for Guizhou to cooperate with ASEAN countries are becoming more and more noticeable. In the future, to strengthen Guizhou-ASEAN higher education cooperation and exchange, Guizhou should minimize the unfavorable factors and maximize the advantages, especially the following major advantages:

Good location and convenient transportation. Guizhou is close to ASEAN countries, particularly central south peninsula countries, though it does not share border with them by land or by sea. But it is a hub in Southwest China to connect North and South, and it is also a strategically important node on the gateway to the sea in Southwestern China. More importantly, the infrastructure in Guizhou has been thoroughly improved in recent decades. It has been turned from a disadvantaged province with poor transportation into one of the best transportation hubs in Southwest China. Guizhou is now one of the few provinces in China whose highway is well connected with all its counties (Zhou, Li, \& He, 2015). Currently, there are 10 airports and one of them is an international airport. Besides, there are Chengdu-Guiyang, Guiyang-Guangzhou, and Shanghai-Kunming high-speed railways going through Guangzhou from all directions. For example, Bangkok can be reached in less than 10 hours from Guiyang either by air or by high-speed railway.

Low cost of living and favorable study and living environment. As for a student, who wants to study abroad, cost of living he/she can afford is the first concern when making the decision. As China is rising rapidly in a comprehensive way, it is a better choice to go studying in China than in the U.S. and Europe, where an international student is expected to pay more money for the education. China, as the second largest economy in the world, is still the largest developing country, whose living cost is much lower than developed countries, especially in Guizhou. Meanwhile, Guizhou and ASEAN countries have something in common in culture and customs, students from ASEAN will find themselves easier to adapt to life in Guizhou. As a province with 
diverse ethnic groups, Guizhou is culturally compatible with ASEAN countries (Zhang \& Luo, 2014). Additionally, Guizhou boasts with well-preserved natural resources and ecological system, including green mountains and clear waters, cool and cheerful weather in summer (The average temperature of Guizhou in summer is never above 25 celsius degrees), high forest coverage rate (57\%), and fresh air (The daily air quality average always remains above 97\%) (Lai \& Liu, 2019). What is more important, the study environment is suitable for them. Some programs or disciplines, which ASEAN students need most, such as agricultural technology, engineering, computer information science, rail transportation, big data science and technology, etc., are available at universities and colleges in Guizhou.

Great policy and financial supports from the central government of China. As a less developed province, the special care and full support from central government is inseparable to the rapid development of Guizhou. In fact, today's extraordinary achievement in Guizhou-ASEAN higher education cooperation and exchange, to a large extent, is the result of the great assistance from the central government. To attain the set goal of lifting poverty and realizing the moderately prosperous society by 2020, Guizhou is going through a period of rapid development. Under this background, CAECW was permanently set up in Guizhou in 2008. Up to now, the education exchange platform has developed into an important plural exchange platform of politics, economy, and culture after 12 years, which has brought a large number of cooperation projects, exchange opportunities, and huge funds to both Guizhou and ASEAN countries. In the future, the cooperation and exchanges of higher education between Guizhou and ASEAN should make most of this important platform by performing the signed cooperation agreements, implementing the projects reached by the two parties and consolidating the established research centers or bases, such as Educational Foreign Aid Base of the Ministry of Education, China-ASEAN Research Center, Demonstration Base for International Students in China, Demonstration Base for China (Guizhou)-ASEAN Overseas Students, China (Guizhou)-Malaysia Education Service Center, Confucius Institutes, Overseas Students Innovation Park, etc..

Abundant tourist resources in Guizhou. Blessed with the well-preserved ecological system, the beautiful natural scenery, colorful ethnic cultures, delicious foods, high-quality organic tea, and the world-famous Kweichou Maotai liquor, Guizhou is now rising as an emerging big tourist province, a rival for Yunnan province, which is well known for its booming tourist industry. In 2018, Guizhou has been the largest tourist destination for ASEAN countries, from which the tourists have reached 200,000, equally, ASEAN countries have also become the largest tourist destination for Guizhou, from which the tourists have reached 120,000 (Wang, 2019). In beefing up the international education cooperation and exchange, the advantage of tourist resources in Guizhou should be fully taken, such as in hosting Guizhou-ASEAN youth summer camps and other exchange activities.

\section{Future Development of Guizhou-ASEAN Higher Education Cooperation and Exchange}

Although today's world is undergoing profound changes, peace and development remain the mainstream for the whole world, and mutual benefit and win-win are the only way out for constructing the community with a shared future for humanity. As China-ASEAN strategic partnership strengthens, Guizhou-ASEAN higher education cooperation and exchange has entered a new phase, in which both quantity and quality are pursued. Therefore, the following aspects should be taken into consideration in promoting Guizhou-ASEAN higher education cooperation and exchange:

Expanding the enrollment size of Guizhou-ASEAN international higher education. So far, the total 
number of ASEAN students studying in Guizhou has not reached 10,000 yet though it is still growing, while the total number of both ASEAN students studying in China and Chinese students studying in ASEAN has already exceeded 100,000 in recent years respectively since the launch of "China-ASEAN Double 100,000 Plan" in 2009, according to which international students from both sides will have reached 100,000 by 2020 respectively (Welch, 2012; Yang, 2016). So, keeping on enlarging the enrollment scale of Guizhou-ASEAN international students is still a priority for boosting the mutual cooperation and exchange of higher education.

Improving the quality of Guizhou-ASEAN higher education cooperation and exchange. Along with the expansion of the enrollment size, the quality of international education should be pursued as well. Either "take in students from ASEAN" or "send out students to ASEAN", educational quality standards must be adhered to. Otherwise, no qualified talents can be cultivated. Some ASEAN students, for example, have been forced to drop out of school as their Chinese proficiency is too poor.

Highlighting the distinctive feature in bilateral or multilateral collaboration. Due to the great impact of globalization, Guizhou higher education internationalization is inclined to be homogenous. In face of severe competition in international cooperation and exchange of higher education, Guizhou should not only learn from Guangxi and Yunnan, but also make prominent its own features. For example, Guizhou should focus on its unique educational resources in cooperation and exchange with ASEAN countries, such as tourism, traditional Chinese medicine for ethnic minorities, big data science and technology, cultures of ethnic groups, etc.. In the current era of globalization, distinctive feature is an edge in international collaboration.

Treating ASEAN countries differently according to their specific needs. As previously mentioned, ASEAN countries are characterized by ethnic, cultural, religious, and linguistic diversities. What is more, they are different from each other in politics and economy. Generally speaking, ASEAN countries can be divided into two types at least: the economically developed and the economically undeveloped. Countries, like Singapore, Malaysia, Indonesia, Thailand, and Philippines, are more economically prosperous than the others, such as Brunei, Vietnam, Laos, Myanmar, and Cambodia. Different countries have different situations and needs in their social and economic development. Regarding this, Guizhou should strengthen the cooperation and exchange with each of them by meeting their respective social needs.

\section{Concluding Remarks}

It has been 16 years since the establishment of China-ASEAN strategic partnership in 2003. The relationship between China and ASEAN has entered a new era, in which political security, economic and trade cooperation, and people-to-people exchanges are the three powerful driving forces for enhancing the strategic partnership. As a part of people-to-people exchanges between China and ASEAN, Guizhou-ASEAN higher education cooperation and exchange is bound to play an increasingly important role in promoting regional stability and prosperity, especially it will play a more and more active part in speeding up the opening up of Guizhou to the outside world and expanding its international influence.

In conclusion, the internationalization of education, higher education cooperation and exchange in particular, is the best option to project influence of a country, enhance its image in the international community and promote its sustainable economic development. As peacefully rising China is moving closer to the center of the world stage, fast-developing Guizhou will be presented with more golden opportunities and unprecedented challenges. Led and driven by the cooperation and exchange of higher education between Guizhou and ASEAN countries, Guizhou will certainly rush out of the great mountains to embrace the outside world. 


\section{References}

Chen, B. (2012). Language situation of the ASEAN countries and Guangxi foreign language Strategy. Journal of Foreign Languages, 35(1), 77-82.

Chen, J. (2018). Yunnan runs 15 overseas Confucius institutes, ranking on the top of the list of opening up education to the outside world. China News Service Website. Retrieved November 24, 2018, from http://www.chinanews.com/cul/2018/1124/8684546.shtml

Chen, G. (2016). China-ASEAN Education Conference Opens and ASEAN students in China has reached 72,000. Guizhou Metropolis Newspaper (4th ed.), 2016/08/03.

Huang, J. (2019). Economic growth rate ranks first nationwide for two consecutive years. Guizhou Daily (1st ed.), 2019/02/04/.

Huo, J. K. (2011). Considerations on the leading roles of Guizhou higher education institutions in expanding the opening up to the outside world. Guizhou Education, (21), 4-6.

Huo, R. (2018). Educational internationalization in ASEAN countries in recent 30 years. Jiangsu Higher Education, (12), $42-47$.

Kirkpatrick, A., \& Liddicoat, A. J. (2017). Language education policy and practice in east and southeast Asia. Language Teaching, $1-34$.

Lai, Y. Y., \& Liu, Z. F. (2019). 24 hours in the $24^{\circ} \mathrm{C}$ summer in Guizhou. Guizhou Daily (6th ed.), 2019/07/12.

Li, B. (2019). Create international flagship brands by converging media and narrate a story of Guizhou to the world. Colorful Guizhou Website. Retrieved March 20, 2019, from http://www.gog.cn/zonghe/system/2019/03/20/017168342.shtml

Lin, H., \& Lin, Y. H. (2015). Guangxi has become the first choice for ASEAN students to study abroad. China News Website. Retrieved October 12, 2015, from http://www.cankaoxiaoxi.com/society/20151229/1040909.shtml

Lin, S. (2015). China-ASEAN marches towards the community with a shared future hand in hand. Xinhuanet. Retrieved October 12, 2015, from http://www.xinhuanet.com/world/2015-10/12/c_128306979.htm

Pang, G. P., \& Xie, J. W. (2010). ASEAN students in Guangxi increased 15 folds in the past decade. Overseas Chinese Education, (6), 14-15.

Ren, Q. X. (2019). Serving well as a bridge for China-ASEAN cooperation and exchanges. Guizhou Daily (6th ed.), 2019/07/25.

Shen, M. X. (2002). On the revelation of ASEAN's experience in developing education to the developing of education in Guizhou. Journal of Guizhou Education Institute, 18(69), 9-13.

Wang, Y. (2015). Guizhou University builds Southeast Asia overseas students training base. Guizhou Daily (1st ed.), 2015/08/01.

Wang, Y. (2019). China-ASEAN Education Cooperation Week 2019 Opens in Guiyang Today, Opening up and Colorful Guizhou Welcomes Friends from all Corners of the World: Share the Developmental Fruits of Pragmatic Cooperation. Guizhou Daily (1st ed.), 2019/07/22.

Welch, A. (2012). China-ASEAN relations in higher education: An analytical framework. Frontiers of Education in China, 7(4), 465-485.

Xia, J. (2018). Talk about Guangxi with statistical figures: Overseas students studying in Guangxi grow by $20 \%$ on average annually in recent 5 years. Xinhuanet. Retrieved December 7, 2018, from https:/finance.sina.com.cn/roll/2018-12-07/docihmutuec7068763.shtml

Yang, C. (2016). China and ASEAN will send more than 100,000 overseas students to each other. China News Net. Retrieved July 11, 2016, from http://www.asean-china-center.org/2016-07/11/c_135503414.htm

Yang, G. (2017). The "Belt and Road Initiative” new challenges-10 years of review and outlook on "China-ASEAN Education Cooperation Week”. Contemporary Guizhou, 2017/07/27, 16-18.

Yu, Q. R. (2019). Overseas students studying in Yunnan rank the ninth on the list nationwide. Yunnan Information Newspaper (3 rd ed.), 2019/07/26.

Zhang, C. X., \& Luo, J. M. (2014). Influences of Chinese culture in Southeast Asian countries. Around Southeast Asia, (6), 59-62.

Zhang, C. X., \& Hu, Y. R. (2016). Experience and practice of internationalization of higher education in Thailand-Taking survey on degree in international cooperation as an example. Around Southeast Asia, 87-93.

Zhang, C. X., Yang, Y. X., Zhou, B., \& Hu, Y. R. (2015). A SWOT analysis on Guizhou's education cooperation with ASEAN countries. Journal of Guiyang University, 10(6), 88-94.

Zhong, J. F. (2019). Statistics on international students studying in China in 2018. The Ministry of Education Website. Retrieved April 12, 2019, from http://www.moe.gov.cn/jyb_xwfb/gzdt_gzdt/s5987/201904/t20190412_377692.html

Zhou, X., Li, J., \& He, J. Y. (2015). Guizhou has become the first province in West China to connect every county by its high ways. Xinhuanet. Retrieved December 31, 2015, from http://news.ifeng.com/a/20151231/46907704_0.shtml 
Zhu, M. F., Huang, K., \& Hu, D. H. (2018). A study on the status quo of the education of international students from ASEAN and its countermeasures. Journal of Taiyuan Urban Vocational College, (1), 84-87. 